\title{
GMR
}

\section{Salicylic acid-induced changes in physiological parameters and genes of the flavonoid biosynthesis pathway in Artemisia vulgaris and Dendranthema nankingense during aphid feeding}

\author{
Y. Sun*, X.L. Xia*, J.F. Jiang, S.M. Chen, F.D. Chen and G.S. Lv \\ College of Horticulture, Nanjing Agricultural University, Weigang, Nanjing, China \\ *These authors contributed equally to this study. \\ Corresponding author: F.D. Chen \\ E-mail: chenfd@njau.edu.cn \\ Genet. Mol. Res. 15 (1): gmr.15017546 \\ Received August 28, 2015 \\ Accepted November 6, 2015 \\ Published February 19, 2016 \\ DOI http://dx.doi.org/10.4238/gmr.15017546
}

\begin{abstract}
Phloem-feeding aphids cause serious damage to plants. The mechanisms of plant-aphid interactions are only partially understood and involve multiple pathways, including phytohormones. In order to investigate whether salicylic acid (SA) is involved and how it plays a part in the defense response to the aphid Macrosiphoniella sanbourni, physiological changes and gene expression profiles in response to aphid inoculation with or without SA pretreatment were compared between the aphid-resistant Artemisia vulgaris 'Variegata' and the susceptible chrysanthemum, Dendranthema nankingense. Changes in levels of reactive oxygen species, malondialdehyde (MDA), and flavonoids, and in the expression of genes involved in flavonoid biosynthesis, including PAL (phenylalanine ammonia-lyase), CHS (chalcone synthase), $\mathrm{CHI}$ (chalcone isomerase), $\mathrm{F} 3 \mathrm{H}$ (flavanone 3-hydroxylase), $\mathrm{F} 3^{\prime} H$ (flavanone
\end{abstract}


3'-hydroxylase), and $D F R$ (dihydroflavonol reductase), were investigated. Levels of hydrogen peroxide, superoxide anions, MDA, and flavonoids, and their related gene expression, increased after aphid infestation and SA pretreatment followed by aphid infestation; the aphid-resistant $A$. vulgaris exhibited a more rapid response than the aphid-susceptible $D$. nankingense to SA treatment and aphid infestation. Taken together, our results suggest that $\mathrm{SA}$ could be used to increase aphid resistance in the chrysanthemum.

Key words: Aphid; Chrysanthemum; Flavonoid; Physiology; Salicylic acid

\section{INTRODUCTION}

Aphids are major agricultural pests, and are specialized to feed on phloem by penetrating plant tissues via a primarily intercellular route, and ingest phloem sap from host plants through stylets. Aphids not only cause a reduction in quality, but are also important vectors of plant viruses (Ng and Perry, 2004). Damage caused by aphids includes leaf rolling, chloroplast degradation, and inflorescence folding.

Plants use constitutive and induced defenses to protect themselves from herbivore attack; these defenses can influence herbivore feeding, development, and oviposition. Constitutive defenses include physical barriers (cell walls, suberin, and callose) that impede herbivore access to tissues (Walling, 2000); plants can also activate the biosynthesis of secondary metabolites (alkaloids, terpene, phenolics, and flavonoids) that have antixenotic or antibiotic properties to deter herbivore growth, development, and reproduction (Leszczynski et al., 1989). Flavonoids are natural plant products that are found in fruits, vegetables, and grains. They include flavones, isoflavones, flavanones, and flavonols (Treutter, 2006). They play important roles in plants, such as being responsible for flower color, stress protection, and the regulation of auxin transport (Nugroho et al., 2002). Flavonoids are derived from the phenylpropanoid pathway, which is catalyzed by a number of enzymes including PAL (phenylalanine ammonia-lyase), CHS (chalcone synthase), $\mathrm{CHI}$ (chalcone isomerase), F3H (flavanone 3-hydroxylase), F3'H (flavanone 3'-hydroxylase), and DFR (dihydroflavonol reductase) (Figure 1). For induced defenses, plants increase the level of reactive oxygen species (ROS) and malondialdehyde (MDA) in response to aphid attack (Moloi and van der Westhuizen, 2006; Maffei et al., 2007), and aphid feeding can induce localized and plant-wide increases in the mRNA transcription or enzyme activity of several pathogenesis-related proteins, such as peroxidases and chitinases (Moran and Thompson, 2001; Boyko et al., 2006). The results of a previous study indicated that transcripts of PR-1 (also known as P4), a salicylic acid (SA)-inducible gene, accumulate in Mi-1 plants after potato aphid (Macrosiphum euphorbiae) feeding (Martinez de Ilarduya et al., 2003). Another study showed that leaf epidermal surface morphology and the activity of antioxidant and defense enzymes contribute to aphid resistance in the chrysanthemum (Chrysanthemum grandiflorum) (He et al., 2011). Chrysanthemums may use constitutive and induced defense strategies against aphid feeding; however, little information on gene expression profiles or signaling in response to aphid feeding is available. 


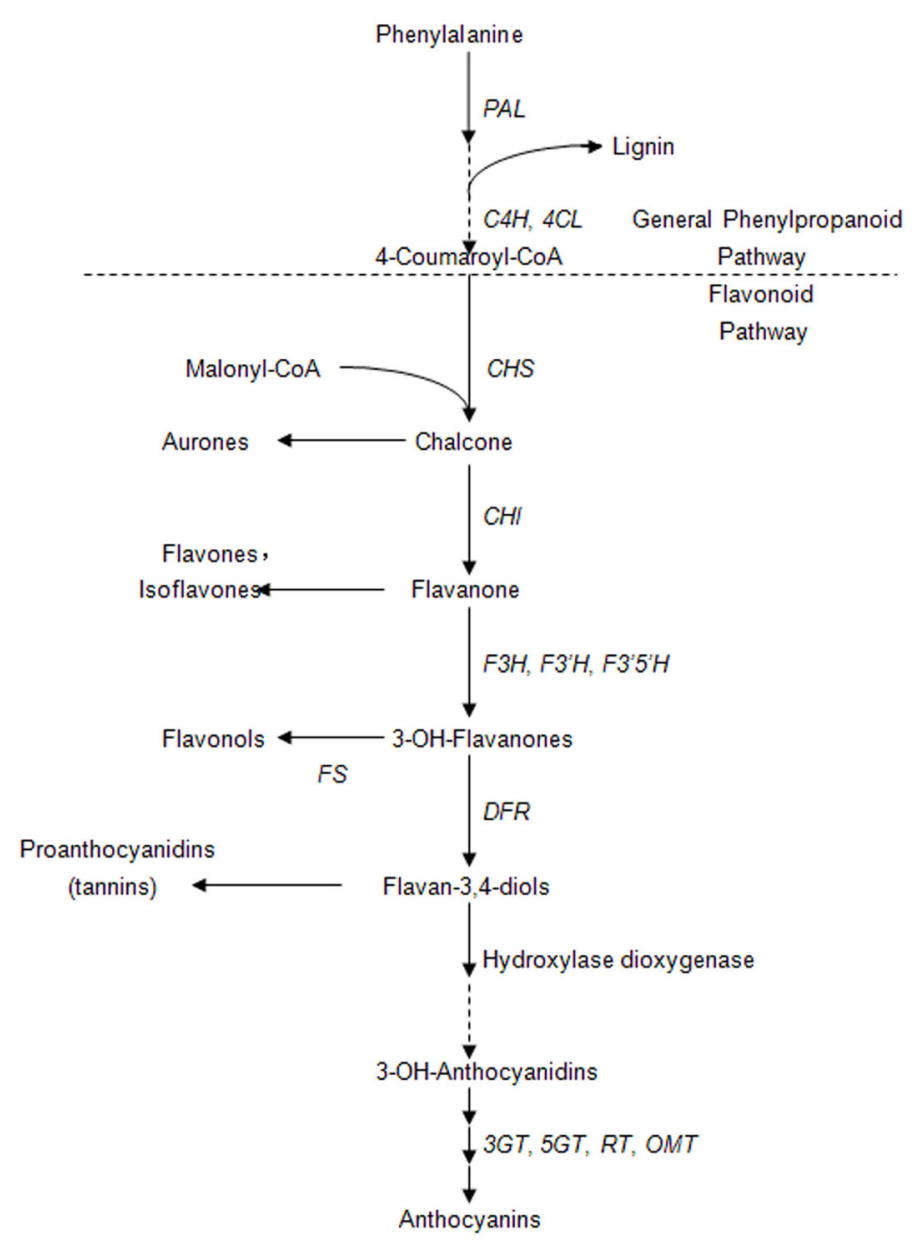

Figure 1. Schematic diagram of the general phenylpropanoid and flavonoid biosynthesis pathways. The dotted line indicates the start of the flavonoid pathway. The genes examined in this study are in italic. Arrows indicate intermediate precursors of other biosynthesis pathways, with final products indicated. $P A L$, phenylalanine ammonia-lyase; $C 4 H$, cinnamate 4-hydroxylase; 4CL, 4-coumaroyl-CoA ligase; $\mathrm{CHS}$, chalcone synthase; $\mathrm{CHI}$, chalcone isomerase; $\mathrm{F} 3 \mathrm{H}$, flavanone 3-hydroxylase; $F 3^{\prime} H$, flavanone 3'-hydroxylase; $F 3^{\prime}{ }^{\prime} H$, flavonoid 3'5'-hydroxylase; $F S$, flavonol synthase; $D F R$, dihydroflavonol reductase; $3 G T$ and $5 G T, 3$ - and 5-glucosyl transferase, respectively; $R T$, rhamnosyltransferase; OMT, O-methyl transferase.

SA has been considered a plant hormone since 1992 (Raskin, 1992), and plays important roles in the regulation of plant growth, development, the response to environmental stress, seed germination, and flowering (Yalpani et al., 1994; Senaratna et al., 2000). SA is also considered an important signaling molecule in plants in response to various pathogenic attacks (Alvarez, 2000), and in resistance to herbivores (Walling, 2000; Cooper et al., 2004). For example, SA induction in aphid-resistant wheat (Triticum aestivum) may be involved in resistance against the Russian wheat aphid (Diuraphis noxia) (Mohase and van der Westhuizen, 2002), and in a wide range of defensive responses in Arabidopsis thaliana against the cabbage aphid, Brevicoryne brassicae (Kusnierczyk et al., 2008). ROS generation is the immediate response of plants to elicit the production of SA. 
ROS mediate different signaling pathways that are associated with plant defense mechanisms, and play roles as secondary messengers in hormone signaling pathways (Alvarez, 2000; Franzen et al., 2008). In addition, SA increases hydrogen peroxide $\left(\mathrm{H}_{2} \mathrm{O}_{2}\right)$ generation (Tewari and Paek, 2011). These observations strongly suggest that the SA signaling pathway is involved in plant responses to aphids, which prompted us to investigate how the exogenous application of this molecule may increase aphid resistance.

The chrysanthemum is an important ornamental plant all over the world, and is susceptible to aphid attack from the seedling to the flowering stages. Artemisia vulgaris (AV) 'Variegata' (mugwort) is an aphid-resistant species due to its leaf morphology and bioactive essential oil content (Deng et al., 2010). Macrosiphoniella sanbourni is a major pest of chrysanthemums, and reduces vegetative growth and flower production and quality. Different chrysanthemum cultivars and closely related wild species exhibit different levels of aphid resistance (Sun et al., 2012). To investigate the effect of exogenous SA on aphid ( $M$. sanbourni) resistance in the chrysanthemum, physiological and molecular changes in response to exogenous SA treatment were compared between $A$. vulgaris (aphid resistant) and the chrysanthemum cultivar, Dendranthema nankingense (DN) (aphid susceptible). We measured levels of ROS, MDA, and flavonoids, and analyzed the expression of flavonoid biosynthesis genes during aphid infestation.

\section{MATERIAL AND METHODS}

\section{Plants and aphids}

AV (aphid resistant) and DN (aphid susceptible) plants were obtained from the Chrysanthemum Germplasm Resource Preserving Centre, Nanjing Agricultural University, China. Seedlings were grown in $15-\mathrm{cm}$ pots, with 12 -h light at $25^{\circ} \mathrm{C}$ and $12-\mathrm{h}$ dark at $18^{\circ} \mathrm{C}$ under a $160 \mathrm{mmol} \cdot \mathrm{m}^{-2} \cdot \mathrm{s}^{-1}$ photon flux density in a greenhouse. Plants were grown to the six to eight leaf stages, and only uniform seedlings were selected for the aphid infestation treatment. Aphids (M. sanbourni Gillette) were collected from field-grown chrysanthemum plants; 2ndinstar nymphs were used to inoculate the plants. The inoculation conditions were $23^{\circ}$ to $28^{\circ} \mathrm{C}$ and $80 \%$ relative humidity.

\section{SA and aphid treatments}

Our preliminary experiments showed that $0.2 \mathrm{mM} \mathrm{SA}$ (solubilized in distilled water, DW) pretreatment for $24 \mathrm{~h}$ was optimal for the inhibition of aphid reproduction in both plant species. For the SA followed by aphid infestation (SAA) treatment, AV and DN plants were sprayed with $0.2 \mathrm{mM}$ SA followed by aphid infestation $24 \mathrm{~h}$ later; the treated samples were designated as AV-SAA and DN-SAA, respectively. For the aphid infestation treatment $(A)$,

AV and DN plants were pretreated by spraying with DW, followed by aphid infestation $24 \mathrm{~h}$ later; the treated samples were designated as AV-A and DN-A, respectively. Control (CK) plants were sprayed with DW without being subjected to aphid infestation $24 \mathrm{~h}$ later; the treated samples were designated as AV-CK or DN-CK. The experiment was replicated three times, and each replicate included 20 seedlings.

The aphid infestation protocol followed the method of Deng et al. (2010). Briefly, five 2nd 
instar aphids were carefully placed on each stem tip of the test plants with a soft brush. All of the plants were covered with polyester cylinders (25 cm long x $12 \mathrm{~cm}$ diameter) with fine gauze, and placed in a greenhouse under the above-mentioned conditions. Leaves, counting from the third leaf below the apex, were collected at $0,3,6,12,24,48,72$, and $168 \mathrm{~h}$ after aphid inoculation (He et al., 2011). At each sampling time point, three biological replications were performed. The sampled leaves were stored at $-70^{\circ} \mathrm{C}$ for the subsequent experiments.

\section{ROS and MDA levels}

The $\mathrm{H}_{2} \mathrm{O}_{2}$ content was measured according to the method described by Libik et al. (2005). Leaf tissue $(1 \mathrm{~g})$ was extracted with $2 \mathrm{~mL}$ cold acetone, centrifuged at 10,000 $\mathrm{g}$ for $5 \mathrm{~min}$, and the supernatant was collected; $0.2 \mathrm{~mL} 20 \%$ titanium reagent in concentrated $\mathrm{HCl}$ was added to $2 \mathrm{~mL}$ supernatant, followed by $0.4 \mathrm{~mL} \mathrm{NH}_{4} \mathrm{OH}$ to precipitate the peroxide-titanium complex. After centrifugation (12,000 g, $5 \mathrm{~min}$ ), the supernatant was discarded and the precipitate dissolved in $2 \mathrm{~mL} 2 \mathrm{~N} \mathrm{H}_{2} \mathrm{SO}_{4}$, washed repeatedly with acetone, and made up to $2 \mathrm{~mL}$ volume. The absorbance was measured at $415 \mathrm{~nm}$ against a DW blank. The $\mathrm{H}_{2} \mathrm{O}_{2}$ concentration was measured by comparing the absorbance against the standard curve at least three times, and was represented as $\mu \mathrm{mol} \cdot \mathrm{g}^{-1} \cdot \mathrm{FW}^{-1}$.

A 1-g leaf sample was milled in $6 \mathrm{~mL} 65 \mathrm{mM}$ phosphate buffered saline (PBS), $\mathrm{pH} 7.8$, filtered, and centrifuged at $5000 \mathrm{~g}$ for $10 \mathrm{~min}$. One milliliter supernatant was mixed with 0.9 $\mathrm{mL} 65 \mathrm{mM}$ PBS and $0.1 \mathrm{~mL} 10 \mathrm{mM}$ oxammonium hydrochloride, and placed in a water bath at $25^{\circ} \mathrm{C}$ for $20 \mathrm{~min}$. The extract was replaced by PBS in the control samples. The assay mixture contained $0.5 \mathrm{~mL} 17 \mathrm{mM}$ 4-aminobenzene sulfonic acid, $0.5 \mathrm{~mL} 7 \mathrm{mM}$ 1-naphthylamine, and 0.5 $\mathrm{mL}$ culture fluid; the reactions were incubated at $25^{\circ} \mathrm{C}$ for $20 \mathrm{~min}$ and terminated by the addition of $1.5 \mathrm{~mL}$ butyl alcohol. The absorbance was measured at $530 \mathrm{~nm}$, and the superoxide anion $\left(\mathrm{O}_{2}^{-}\right)$content was expressed as $\mathrm{nmol} \cdot \mathrm{min}^{-1} \cdot \mathrm{mg}^{-1}$ per protein. Each measurement was repeated at least three times.

The MDA content was determined by the method described by Meng et al. (2007). A leaf sample $(0.2 \mathrm{~g})$ was homogenized with $5 \mathrm{~mL} 10 \%$ trichloroacetic acid (TCA). After centrifugation at $4000 \mathrm{~g}$ for $10 \mathrm{~min}$, the supernatant was mixed with $2 \mathrm{~mL} \mathrm{0.6 \%} \mathrm{2-thiobarbituric} \mathrm{acid} \mathrm{(TBA)} \mathrm{in}$ $10 \%$ TCA, heated in boiling water for $15 \mathrm{~min}$, and then immediately cooled on ice and centrifuged $(10,000 \mathrm{~g}, 10 \mathrm{~min})$. Absorbance of the supernatant at 532 and $450 \mathrm{~nm}$ was compared with that of the blank (2 mL $0.6 \%$ TBA in $10 \%$ TCA, without the extracts) at least three times. The MDA measurement was expressed as $\mu \mathrm{mol} \cdot \mathrm{g}^{-1} \cdot \mathrm{FW}^{-1}$.

\section{Flavonoid determination}

Fresh leaves were cut into small pieces, air-dried, and milled into powder before extraction. The milled powder $(1 \mathrm{~g})$ was extracted with $100 \mathrm{~mL} \mathrm{DW}$ for $1 \mathrm{~h}$. The extract was filtered, transferred, and made up to $5 \mathrm{~mL}$ with $\mathrm{DW}$, and then $0.3 \mathrm{~mL} \mathrm{NaNO}{ }_{2}\left(\mathrm{NaNO}_{2}\right.$ : DW, 20:1, v/v) and $3 \mathrm{~mL}$ aluminum trichloride $\left(\mathrm{AlCl}_{3}: \mathrm{DW}, 1: 10, \mathrm{v} / \mathrm{v}\right)$ were added $5 \mathrm{~min}$ later. After $6 \mathrm{~min}, 2 \mathrm{~mL} 1 \mathrm{M} \mathrm{NaOH}$ was added and the reaction mix was made up to $10 \mathrm{~mL}$ with DW. Absorbance was read at $510 \mathrm{~nm}$ against a blank sample after $15 \mathrm{~min}$. The rutin content was used as the standard for the calibration curve, $A=0.013 \mathrm{C}$ $+0.0056, r=0.9993$, where $A$ represented the absorbance and $C$ the flavonoid content. The flavonoid content was represented as a percentage. Each measurement was repeated three times. 


\section{cDNA synthesis and real-time quantitative reverse transcription polymerase chain reaction (qRT-PCR) analysis}

RNA was isolated from leaf tissue $(0.2 \mathrm{~g})$ using RNAiso reagent (TaKaRa, Japan), following the manufacturer protocol. RNA integrity was assessed with an agarose gel and by an $\mathrm{OD}_{260} / \mathrm{OD}_{280}$ $\mathrm{nm}$ absorption ratio greater than 1.95 . Total RNA $(0.5 \mu \mathrm{g})$ was used for first-strand cDNA synthesis; the reaction volume included $2 \mu \mathrm{L}$ total RNA, $2 \mu \mathrm{L}$ oligo $(\mathrm{dT})_{18}$ primer, $9.7 \mu \mathrm{L}$ RNase-free $\mathrm{ddH}_{2} \mathrm{O}$, $4 \mu \mathrm{L} 5 \mathrm{X}$ M-MLV reaction buffer, $1 \mu \mathrm{L}$ dNTP mixture $(10 \mathrm{mM}), 0.5 \mu \mathrm{L}$ RNase inhibitor, and $0.8 \mu \mathrm{L}$ reverse transcriptase (M-MLV, TaKaRa).

The qRT-PCRs were performed in a $25-\mu \mathrm{L}$ volume containing $1 \mu \mathrm{L}$ of each gene-specific

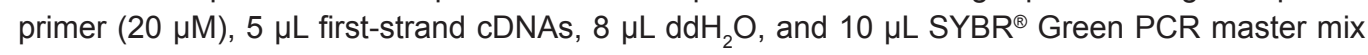
(Toyobo, Japan). The PCR conditions were as follows: denaturation at $95^{\circ} \mathrm{C}$ for $60 \mathrm{~s}$, followed by 40 cycles at $95^{\circ} \mathrm{C}$ for $15 \mathrm{~s}, 55^{\circ} \mathrm{C}$ for $15 \mathrm{~s}$, and $72^{\circ} \mathrm{C}$ for $45 \mathrm{~s}$. At the end of the cycling process, the temperature was increased from $55^{\circ}$ to $95^{\circ} \mathrm{C}$ with a $0.5^{\circ} \mathrm{C} / \mathrm{s}$ heating rate, in order to obtain the necessary denaturation curve. Amplicon purity was assumed where a single melting peak was produced. The sequences of each PCR primer (Table 1) that shared consensus sequences in both species were designed using Primer 3 (v. 0.4.0). Three replicates of each sample were performed, and PCR efficiency was calculated by the $2^{-\Delta \Delta c t}$ method (Livak and Schmittgen, 2001).

Table 1. Primers used in the real time quantitative reverse transcription polymerase chain reaction.

\begin{tabular}{l|l|l}
\hline Gene & GenBank accession No. & Primer pair \\
\hline PAL (phenylalanine ammonia lyase) & JF806362 & F: GATTGTTCTTTGTTTGCTCAT \\
\hline CHS (chalcone synthase) & & R: CTTAACCATTTTTTTAACCTCA \\
\hline CHI (chalcone isomerase) & DQ521272.1 & F: CAAGCCTTTTCTCCATTAGGT \\
\hline F3'H (flavanone 3'-hydroxylase) & & R: GAGGACCACGGTTTCGAC \\
\hline & EU286277. 1 & F: TGGTGCAACCATTGACAAGT \\
\hline F3 'H (flavanone 3'-hydroxylase) & & R: AAATTTGGTTCAGCATCTGTAGTT \\
\hline & EU286276. 1 & F: CATTATTTGAGCAACGGAAGA \\
\hline DFR (dihydroflavonol 4-reductase) & & R: TGCCAATCTCTAAGCCAAGAT \\
\hline & EF094936. 2 & F: TTGGGGCTGGACGAAGGATT \\
\hline
\end{tabular}

F, forward primer; $R$, reverse primer.

\section{Statistical analysis}

A one-way analysis of variance was conducted for all of the parameters studied, and the Duncan multiple range test $(P=0.05)$ was used to assess whether means significantly differed from one another in SPSS v. 13.0.

\section{RESULTS}

\section{Aphid numbers}

SA pretreatment decreased the number of aphids on both plant species. The average 
numbers of aphids on the AV-SAA (2.00) and DN-SAA (4.33) plants were significantly lower than those on the AV-A (3.35) and DN-A (4.99) plants, respectively, at 3 days after infestation (DAI) (Table 2). There were significantly fewer aphids on the AV-SAA plants (2.00) than on the DN-A (4.99) or DN-SAA (4.33) plants at $3 \mathrm{DAI}(\mathrm{P}<0.05)$, and aphids were undetectable at $12 \mathrm{DAI}$ on the AV-SAA plants, three days earlier than on the AV-A plants (15 DAI).

Table 2. Average numbers of aphids at different days after aphid inoculation and SAA treatment.

\begin{tabular}{l|c|c|c|c|c|c|c|c}
\hline \multicolumn{9}{|c|}{ Inoculation days } \\
\hline Treatment & 0 day & 3 days & 6 days & 9 days & 12 days & 15 days & 18 days & 21 days \\
\hline AV-A & $5.00 \pm 0.00^{\mathrm{a}}$ & $3.35 \pm 0.11^{\mathrm{a}}$ & $2.63 \pm 0.10^{\mathrm{a}}$ & $0.50 \pm 0.03^{\mathrm{a}}$ & $0.38 \pm 0.01^{\mathrm{a}}$ & $0.00 \pm 0.00^{\mathrm{a}}$ & $0.00 \pm 0.00^{\mathrm{a}}$ & $0.00 \pm 0.00^{\mathrm{a}}$ \\
\hline AV-SAA & $5.00 \pm 0.00^{\mathrm{a}}$ & $2.00 \pm 0.06^{\mathrm{b}}$ & $1.88 \pm 0.18^{\mathrm{b}}$ & $0.25 \pm 0.02^{\mathrm{a}}$ & $0.00 \pm 0.00^{\mathrm{a}}$ & $0.00 \pm 0.00^{\mathrm{a}}$ & $0.00 \pm 0.00^{\mathrm{a}}$ & $0.00 \pm 0.00^{\mathrm{a}}$ \\
\hline DN-A & $5.00 \pm 0.00^{\mathrm{a}}$ & $4.99 \pm 0.24^{\mathrm{c}}$ & $8.01 \pm 0.15^{\mathrm{c}}$ & $35.14 \pm 1.20^{\mathrm{b}}$ & $53.83 \pm 2.25^{\mathrm{b}}$ & $62.57 \pm 0.64^{\mathrm{b}}$ & $65.64 \pm 1.27^{\mathrm{b}}$ & $79.14 \pm 1.53^{\mathrm{b}}$ \\
\hline DN-SAA & $5.00 \pm 0.00^{\mathrm{a}}$ & $4.33 \pm 0.13^{\mathrm{d}}$ & $6.64 \pm 0.10^{\mathrm{d}}$ & $9.37 \pm 0.13^{\mathrm{c}}$ & $23.43 \pm 0.07^{\mathrm{c}}$ & $29.60 \pm 0.97^{\mathrm{c}}$ & $32.35 \pm 1.18^{\mathrm{c}}$ & $41.22 \pm 0.78^{\mathrm{c}}$ \\
\hline
\end{tabular}

SA, salicylic acid; SAA, SA pretreatment followed by aphid infestation; AV-A, aphid inoculation in Artemisia vulgaris 'Variegata'; AV-SAA, SA pretreatment followed by aphid infestation in A. vulgaris; DN-A, aphid inoculation in Dendranthema nankingense; DN-SAA, SA pretreatment followed by aphid infestation in $D$. nankingense. The experiment was replicated three times, and each replicate included 20 seedlings. Values (means \pm SD) labeled with a different letter differed significantly from one another at the same time point according to the Duncan multiple range test $(P<0.05)$.

\section{ROS and MDA generation}

In the AV-A and AV-SAA plants, the $\mathrm{H}_{2} \mathrm{O}_{2}$ content increased and reached a maximum at $6 \mathrm{~h}$ (13.81 $\left.\mathrm{mmol} \cdot \mathrm{g}^{-1} \cdot \mathrm{FW}^{-1}\right)$ and $3 \mathrm{~h}\left(8.93 \mathrm{mmol} \cdot \mathrm{g}^{-1} \cdot \mathrm{FW}^{-1}\right)$, respectively. The $\mathrm{H}_{2} \mathrm{O}_{2}$ content of the AV-SAA plants was maintained at a relatively high level after $72 \mathrm{~h}$ in comparison to that of the AV-A plants. In the DN-A and DN-SAA treatments, the $\mathrm{H}_{2} \mathrm{O}_{2}$ content increased and reached a maximum at 12 $\mathrm{h}\left(20.06 \mathrm{mmol} \cdot \mathrm{g}^{-1} \cdot \mathrm{FW}^{-1}\right)$ and $6 \mathrm{~h}\left(11.90 \mathrm{mmol} \cdot \mathrm{g}^{-1} \cdot \mathrm{FW}^{-1}\right)$, respectively. The levels in the DN-SAA plants were significantly lower than those in the DN-A plants throughout the aphid-feeding period $(P<0.05$; Figure 2).

The $\mathrm{O}_{2}^{-}$content in the AV-A and DN-A plants increased up to $12 \mathrm{~h}\left(0.24 \mathrm{nmol} \cdot \mathrm{min}^{-}\right.$ $1 \cdot \mathrm{mg}^{-1}$ per protein) and $72 \mathrm{~h}\left(0.49 \mathrm{nmol} \cdot \mathrm{min}^{-1} \cdot \mathrm{mg}^{-1}\right.$ per protein), respectively, and then decreased. In the AV-SAA plants, the $\mathrm{O}_{2}{ }^{-}$content reached a maximum at $3 \mathrm{~h}\left(0.15 \mathrm{nmol} \cdot \mathrm{min}^{-}\right.$ ${ }^{1} \cdot \mathrm{mg}^{-1}$ per protein), had decreased by $12 \mathrm{~h}$, increased again to a second peak at $72 \mathrm{~h}$, and then decreased by $168 \mathrm{~h}$. A similar pattern was observed in the DN-SAA plants, except that the first peak occurred at $6 \mathrm{~h}\left(0.29 \mathrm{nmol} \cdot \mathrm{min}^{-1} \cdot \mathrm{mg}^{-1}\right.$ per protein) (Figure 3$)$. The increase in the $\mathrm{O}_{2}$ - content in the AV-SAA and DN-SAA plants was lower than that in the AV-A and DN-A plants, respectively (Figure 3 ).

The MDA content increased after aphid inoculation and the SAA treatment (Figure 4). In the AV-A plants, changes in the MDA content were similar to changes in the $\mathrm{H}_{2} \mathrm{O}_{2}$ content. Changes in the MDA level in the AV-SAA plants were similar to those in the AV-A plants, except that the first peak occurred at $3 \mathrm{~h}\left(34.59 \mathrm{nmol} \cdot \mathrm{g}^{-1} \cdot \mathrm{FW}^{-1}\right)$ rather than $6 \mathrm{~h}(48.03$ $\left.\mathrm{nmol} \cdot \mathrm{g}^{-1} \cdot \mathrm{FW}^{-1}\right)$ in the AV-A plants, and there was no significance difference between them after $24 \mathrm{~h}$. In the DN-A plants, MDA levels rapidly increased by $12 \mathrm{~h}$ and reached a peak at $48 \mathrm{~h}\left(60.64 \mathrm{nmol} \cdot \mathrm{g}^{-1} \cdot \mathrm{FW}^{-1}\right)$. In the DN-SAA plants, the level was always significantly lower than that in the DN-A plants $(P<0.05)$, and the highest level was observed at $24 \mathrm{~h}(46.02$ $\left.\mathrm{nmol} \cdot \mathrm{g}^{-1} \cdot \mathrm{FW}^{-1}\right)$ (Figure 4$)$. 


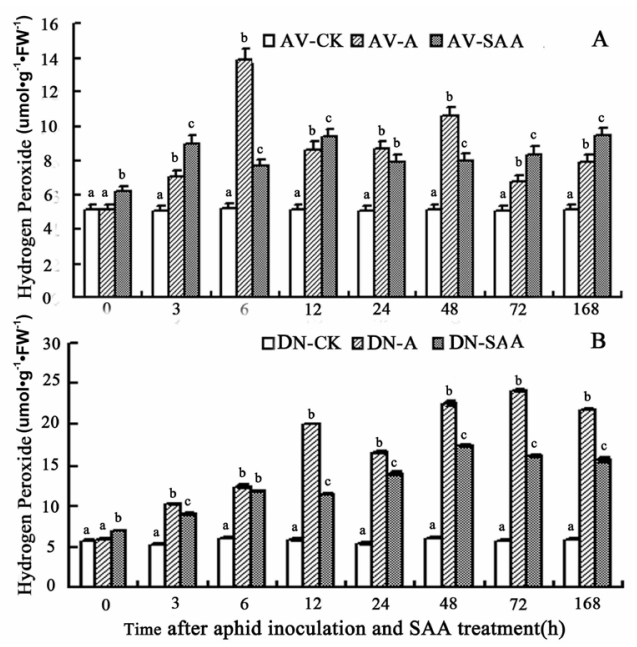

Figure 2. Effect of aphid inoculation and SAA treatment on hydrogen peroxide levels in aphid-resistant Artemisia vulgaris 'Variegata' and aphid-susceptible Dendranthema nankingense. SA, salicylic acid; SAA, SA pretreatment followed by aphid infestation; AV-CK, A. vulgaris sprayed only with distilled water; AV-A, aphid inoculation in A. vulgaris; AV-SAA, SA pretreatment followed by aphid infestation in $A$. vulgaris; DN-CK, $D$. nankingense sprayed only with distilled water; DN-A, aphid inoculation in $D$. nankingense; DN-SAA, SA pretreatment followed by aphid infestation in $D$. nankingense. Values are reported as means $\pm S D(N=3)$. Values labeled with a different letter differed significantly from one another at the same time point according to the Duncan multiple range test $(P<0.05)$.

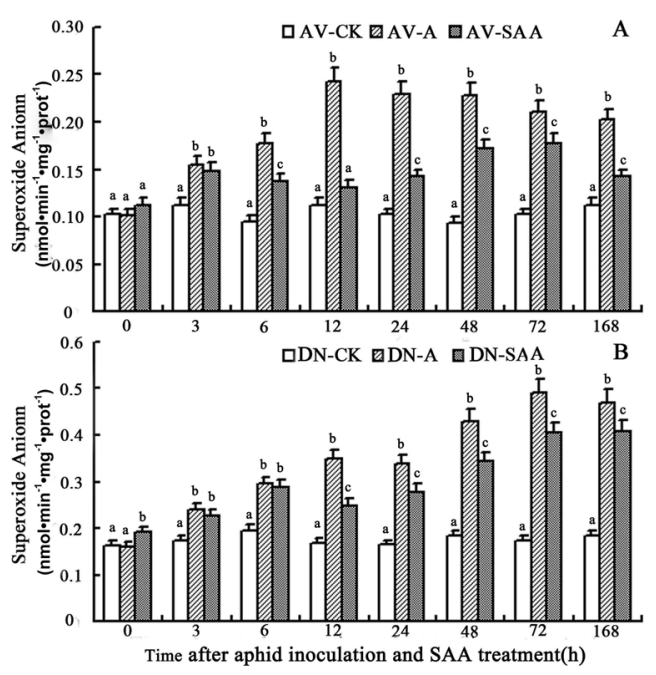

Figure 3. Effect of aphid inoculation and SAA treatment on superoxide anion levels in aphid-resistant Artemisia vulgaris 'Variegata' and aphid-susceptible Dendranthema nankingense. SA, salicylic acid; SAA, SA pretreatment followed by aphid infestation; AV-CK, A. vulgaris sprayed only with distilled water; AV-A, aphid inoculation in A. vulgaris; AV-SAA, SA pretreatment followed by aphid infestation in A. vulgaris; DN-CK, D. nankingense sprayed only with distilled water; DN-A, aphid inoculation in $D$. nankingense; DN-SAA, SA pretreatment followed by aphid infestation in $D$. nankingense. Values are reported as means $\pm S D(N=3)$. Values labeled with a different letter differed significantly from one another at the same time point according to the Duncan multiple range test $(P<0.05)$. 

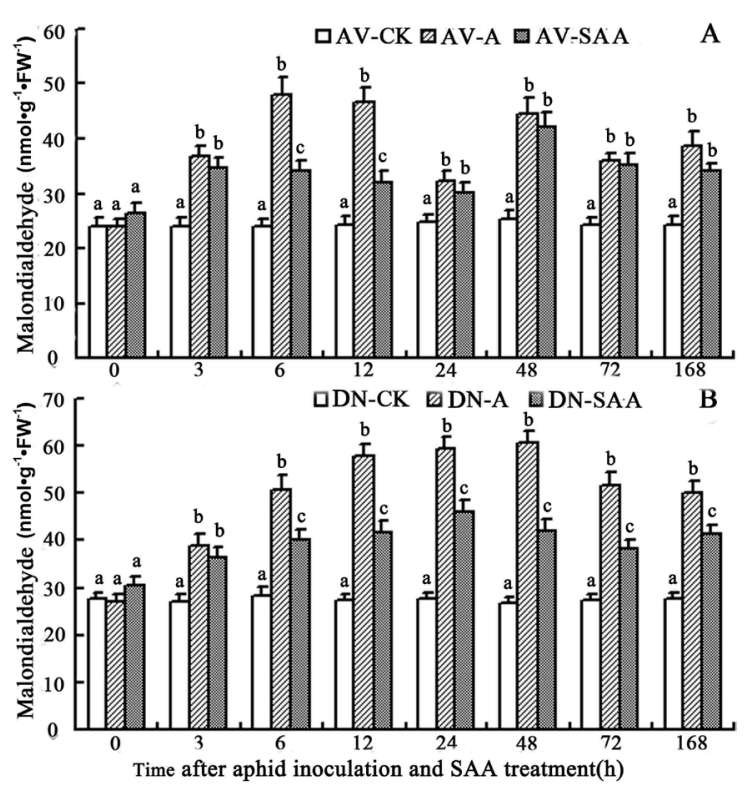

Figure 4. Effect of aphid inoculation and SAA treatment on malondialdehyde levels in aphid-resistant Artemisia vulgaris 'Variegata' and aphid-susceptible Dendranthema nankingense. SA, salicylic acid; SAA, SA pretreatment followed by aphid infestation; AV-CK, A. vulgaris sprayed only with distilled water; AV-A, aphid inoculation in A. vulgaris; AV-SAA, SA pretreatment followed by aphid infestation in $A$. vulgaris; DN-CK, D. nankingense sprayed only with distilled water; DN-A, aphid inoculation in $D$. nankingense; DN-SAA, SA pretreatment followed by aphid infestation in $D$. nankingense. Values are reported as means $\pm S D(N=3)$. Values labeled with a different letter differed significantly from one another at the same time point according to the Duncan multiple range test $(P<0.05)$.

\section{Variations in flavonoid content and the expression of genes involved in the flavonoid biosynthesis pathway}

In the AV-SAA plants, the flavonoid level was significantly higher than in the AV-A plants throughout the aphid-feeding period, except at $24 \mathrm{~h}(\mathrm{P}<0.05$; Figure 5). The highest level was observed in the AV-SAA plants at $12 \mathrm{~h}(5.87 \%)$, which was maintained up to $48 \mathrm{~h}$; in the AV-A plants, the flavonoid content reached $4.83 \%$ by $24 \mathrm{~h}$. In the DN-SAA plants, the flavonoid content was higher than that in the DN-A plants (except at $48 \mathrm{~h}$ ), and the highest level was observed at 24 $\mathrm{h}(0.35 \%)$. In the DN-A/SAA plants, the flavonoid content was significantly lower than that in the AV-A/SAA plants throughout the aphid-feeding period $(P<0.05)$.

The expression of genes involved in the flavonoid biosynthesis pathway in the AV/DN-SAA plants was significantly induced by $\mathrm{SA}$ as early as $0 \mathrm{~h}$ (Figure 6). Levels of $P A L, C H S, C H I, F 3 H$, $F 3^{\prime} H$, and DFR expression in the DN-A and DN-SAA plants were significantly lower than those in the AV-SAA plants $(P<0.05)$. In general, the expression of these genes in the AV-SAA plants was significantly higher than in the AV-A plants, with the exception of $P A L$ at 72 and $168 \mathrm{~h}$ (Figure 6A), $\mathrm{CHS}$ at 6, 24, and $48 \mathrm{~h}$ (Figure 6C), $\mathrm{CHI}$ at 6, 72, and $168 \mathrm{~h}$ (Figure 6E), $\mathrm{F} 3 \mathrm{H}$ at 48 and $72 \mathrm{~h}$ (Figure $6 \mathrm{G}), F 3^{\prime} \mathrm{H}$ at 6 and $168 \mathrm{~h}$ (Figure $6 \mathrm{l}$ ), and DFR at 24 and $72 \mathrm{~h}$ (Figure $\left.6 \mathrm{~K}\right)(\mathrm{P}<0.05)$. A similar difference was observed between the DN-SAA and DN-A plants. 

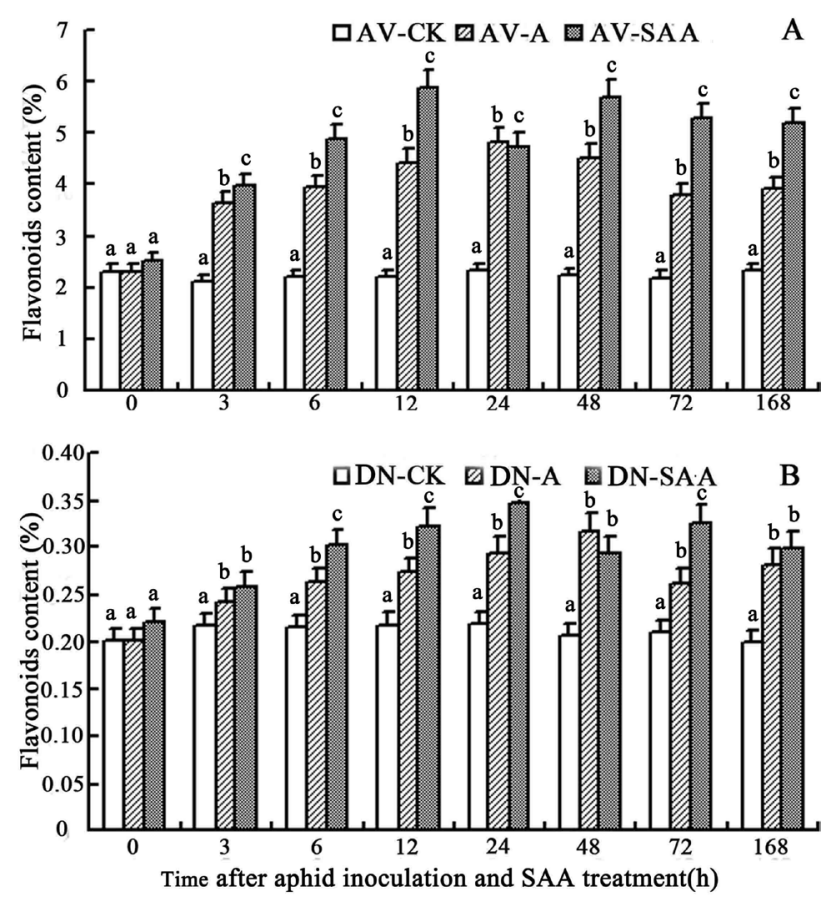

Figure 5. Effect of aphid inoculation and SAA treatment on flavonoid levels in aphid-resistant Artemisia vulgaris 'Variegata' and aphid-susceptible Dendranthema nankingense. SA, salicylic acid; SAA, SA pretreatment followed by aphid infestation; AV-CK, A. vulgaris sprayed only with distilled water; AV-A, aphid inoculation in A. vulgaris; AV-SAA, SA pretreatment followed by aphid infestation in $A$. vulgaris; DN-CK, $D$. nankingense sprayed only with distilled water; DN-A, aphid inoculation in $D$. nankingense; DN-SAA, SA pretreatment followed by aphid infestation in $D$. nankingense. Values are reported as means $\pm S D(N=3)$. Values labeled with a different letter differed significantly from one another at the same time point according to the Duncan multiple range test $(P<0.05)$.

\section{DISCUSSION}

\section{Effect of aphid and SAA treatments on ROS and MDA levels}

Most ROS are short-lived diffusible entities, such as hydroxyl ( $\mathrm{OHe}$ enalkoxyl $\left(\mathrm{RO}^{-}\right)$, and peroxyl $\left(\mathrm{ROO}^{-}\right)$radicals, but also include longer-lived radical species, such as the superoxide anion $\left(\mathrm{O}_{2}^{-}\right)$or nitroxyl (NO). They also include non-radicals, such as $\mathrm{H}_{2} \mathrm{O}_{2}$, organic hydroperoxides $(\mathrm{ROOH})$, and hypochlorous acid $(\mathrm{HClO})$, which also have negative effects on DNA and proteins (Blokhina et al., 2003). Therefore, it is not surprising that ROS are part of a plant defense mechanism against insects. Some studies had found that ROS are elicitors of defense-signaling pathways that are involved in the response to aphid attack (Boyko et al., 2006), and barley, oat, and wheat exhibit increased levels of $\mathrm{H}_{2} \mathrm{O}_{2}$ in response to attack by Schizaphis graminum, D. noxia, and Rhopalosiphum padi (Smith and Boyko, 2007). SA can reduce environmental stress (Horváth et al., 2007) and increase antioxidant damage (Sawada et al., 2008). In the present study, $\mathrm{H}_{2} \mathrm{O}_{2}$ and $\mathrm{O}_{2}$ - levels significantly increased in response to aphid infestation (Figures 2 and 3 ). 

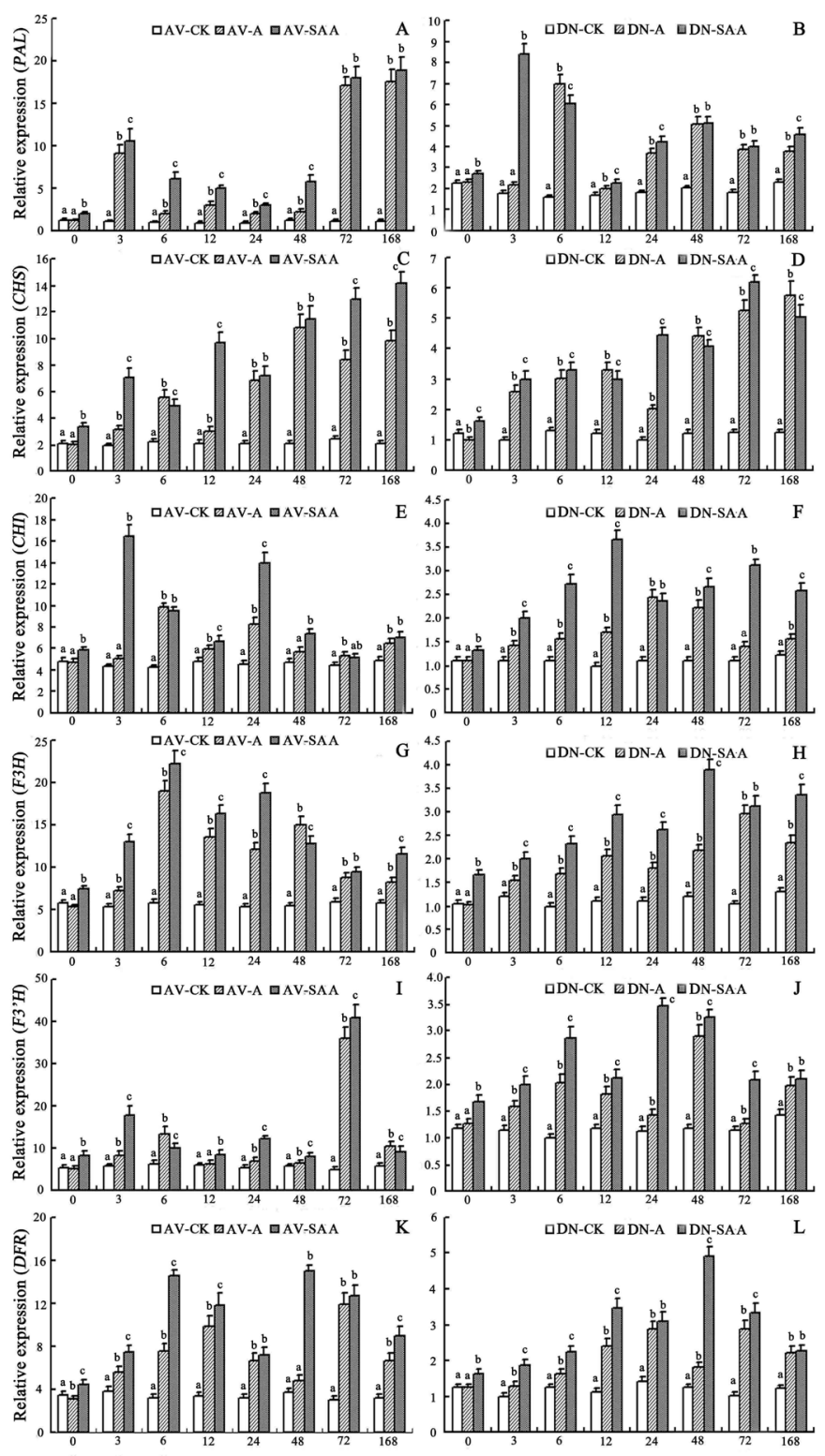

Figure 6. Effect of aphid inoculation and SAA treatment on relative gene expression (PAL, CHS, CHI, F3H, F3'H, and $D F R$ ) in aphid-resistant Artemisia vulgaris 'Variegata' and aphid-susceptible Dendranthema nankingense. SA, salicylic acid; SAA, SA pretreatment followed by aphid infestation; AV-CK, A. vulgaris sprayed only with distilled water; AV-A, aphid inoculation in A. vulgaris; AV-SAA, SA pretreatment followed by aphid infestation in A. vulgaris; DN-CK, $D$. nankingense sprayed only with distilled water; DN-A, aphid inoculation in D. nankingense; DN-SAA, SA pretreatment followed by aphid infestation in $D$. nankingense. The lowest value of the control was set at 1 . Values are reported as means $\pm S D(N=3)$. Values labeled with a different letter differed significantly from one another at the same time point according to Duncan's multiple range test $(P<0.05)$. 
In the aphid-resistant AV, ROS were generated earlier than in the aphid-susceptible DN, and the ROS level in DN was generally higher than that in AV (Figures 2 and 3). ROS induced at an early stage of aphid feeding may act as signaling molecules for the aphid-resistance response, while a high level of ROS at later stages may be an indication of oxidative damage caused by the aphids. Twentyfour-hour SA pretreatment induced early ROS generation (at $0 \mathrm{~h}$ of aphid infestation, Figures 2 and 3 ), suggesting that SA-induced ROS might be involved in aphid-feeding signaling. In contrast, the $\mathrm{O}_{2}^{-}$and $\mathrm{H}_{2} \mathrm{O}_{2}$ levels in SA-pretreated plants after $3 \mathrm{~h}$ were lower than those in the non-SA-pretreated plants (Figures 2 and 3), possibly due to the activity of ROS-scavenging enzymes. In order to investigate this possibility, the activity of antioxidant enzymes such as SOD, CAT, APX, and POX should be measured. The reason for the higher level of $\mathrm{H}_{2} \mathrm{O}_{2}$ in SA-pretreated aphid-resistant AV plants than in non-SApretreated $\mathrm{AV}$ plants eaten by aphids after $72 \mathrm{~h}$ is unknown.

Biotic and abiotic stressors can stimulate the production of ROS and the lipid peroxidation of cell macromolecules, and consequently cause membrane damage to the host membrane (Baker and Orlandi, 1995). Khattab and Khattab (2005) reported that insect herbivory increases lipid peroxidation, as measured by MDA levels. SA is responsible for inducing abiotic stress tolerance in plants, and experimentally applied SA decreases MDA levels that have increased due to salinity stress (Gunes et al., 2007). In our study, MDA levels were higher in the aphid-resistant AV-A plants than in the AV-SAA plants, and those in the AV-A plants were lower than those in the DN-A plants. MDA levels in the SA-pretreated plants were generally lower than those in the non-SApretreated plants (Figure 4), which is consistent with the changes observed in the $\mathrm{H}_{2} \mathrm{O}_{2}$ and $\mathrm{O}_{2}{ }^{-}$ levels, suggesting that MDA is an effective indicator of ROS damage. Lipid peroxidation may be the main effect of aphid feeding, and SA might reduce lipid peroxidation and provide protection from oxidative damage during the late stages of aphid infestation.

\section{Flavonoid content and the expression of genes in the flavonoid synthesis pathway in plants subjected to aphid feeding with or without SA pretreatment}

Flavonoids include flavones, isoflavones, flavanones, and flavonols and are derived from the phenylpropanoid pathway (Treutter, 2006). They play various roles in plants, such as being responsible for the color of flowers, fruits, and leaves, inhibiting the infectivity of tobacco mosaic virus, protecting plants against ultraviolet light, inducing pollen germination, and regulating auxin transport (Shirley, 1996). In addition, flavonoids reduce the nutritive value of plant tissues (Treutter, 2006), consequently protecting plants from insect attack. Beninger and Abou-Zaid (1997) reported that the growth of gypsy moth (Lymantria dispar) larvae is inhibited by the presence of flavonol glycosides in pine needles. Piubelli et al. (2003) reported that seeds damaged by stink bugs (Nezara viridula) had a higher isoflavone content (daidzin and genistin) than controls. In the present study, aphid feeding and SAA treatment both greatly increased the flavonoid content of both plant species, and the aphid-resistant AV had higher levels than the aphid-susceptible DN (Figure 5). This result suggests that flavonoid accumulation is a biochemical response to aphid feeding, and SA can induce flavonoid synthesis and provide effective protection from aphid infestation.

Knowledge of the expression profiles of genes in the flavonoid biosynthetic pathway increases our understanding of flavonoid biosynthesis in response to aphid and SA pretreatment. Zhang et al. (2004) reported that the expression of eight of the seventeen genes in the flavonoid pathway was up- or downregulated when attacked by brown planthoppers (Nilaparvata lugens). 
CHS is considered a rate-limiting enzyme in the flavonoid pathway, and is induced at both the translational and transcriptional levels in Norway spruce (Picea abies) by wounding (Brignolas et al., 1995). Methyl salicylate functions as an airborne signal that activates the expression of defense-related genes in tobacco (Shulaev et al., 1997). In the present study, the expression of flavonoid-responsive genes ( $P A L, C H S, C H I, F 3 H, F 3$ 'H, and DFR) was induced in both resistant and susceptible plants. We found that gene transcription induction occurred more rapidly in the aphid-resistant $\mathrm{AV}$ plants, and the expression levels of these genes in AV plants were higher than those in DN plants (Figure 6). SAA treatment induced an earlier increase in transcriptional levels, and higher expression levels, than aphid infestation alone (Figure 6). The expression levels of genes involved in the flavonoid biosynthetic pathway were consistent with the corresponding flavonoid accumulation (Figures 5 and 6), which suggests that SA increases flavonoid production by increasing the transcription of related genes, consequently increasing aphid resistance. The possibility that SA has a direct deterrent effect cannot be excluded.

There have been several recent studies conducted on plant transcriptomic responses against aphid infestation. Coppola et al. (2013) suggested that the responses are characterized by increased oxidative stress accompanied by the induction of proteins related to ROS detoxification, and that SA-signaling pathway and stress-responsive SA-dependent genes play a dominant role in tomatoaphid interactions, which our results support. In conclusion, our results show that lipid peroxidation is the main effect of aphid feeding, and SA may reduce lipid peroxidation and provide protection from oxidative damage during the late stages of aphid infestation. Flavonoid accumulation is a biochemical response to aphid feeding, and SA can induce flavonoid synthesis. Therefore, SA plays a vital role in plant-aphid interactions, and could be used to increase aphid resistance in chrysanthemum.

\section{Conflicts of interest}

The authors declare no conflicts of interest.

\section{ACKNOWLEDGMENTS}

Research supported by the Program for New Century Excellent Talents in University of Chinese Ministry of Education (\#NCET-10-0492), the Science and Technology Program of Jiangsu Province (\#BE2011325 and \#BE2012350), the "863" Program of Ministry of Science and Technology of P.R. China (\#2011AA100208), the Fund for Independent Innovation of Agricultural Sciences in Jiangsu Province (\#CX(12)2020), and the Project Funded by the Priority Academic Program Development of Jiangsu Higher Education Institutions.

\section{REFERENCES}

Alvarez ME (2000). Salicylic acid in the machinery of hypersensitive cell death and disease resistance. Plant Mol. Biol. 44: 429-442. http://dx.doi.org/10.1023/A:1026561029533

Baker CJ and Orlandi EW (1995). Active oxygen in plant pathogenesis. Annu. Rev. Phytopathol. 33: 299-321. http://dx.doi.org/10.1146/annurev.py.33.090195.001503

Beninger CW and Abou-Zaid MM (1997). Flavonol glycosides from four pine species that inhibit early instar gypsy moth (Lepidoptera: Lymantriidae) development. Biochem. Syst. Ecol. 25: 505-512. http://dx.doi.org/10.1016/S0305-1978(97)00034-3

Blokhina O, Virolainen E and Fagerstedt KV (2003). Antioxidants, oxidative damage and oxygen deprivation stress: a review. Ann. Bot. (Lond.) 91: 179-194.http://dx.doi.org/10.1093/aob/mcf118 
Boyko EV, Smith CM, Thara VK, Bruno JM, et al. (2006). Molecular basis of plant gene expression during aphid invasion: wheat Pto- and Pti-like sequences are involved in interactions between wheat and Russian wheat aphid (Homoptera: Aphididae). J. Econ. Entomol. 99: 1430-1445. http://dx.doi.org/10.1093/jee/99.4.1430

Brignolas F, Lacroix B, Lieutier F, Sauvard D, et al. (1995). Induced responses in phenolic metabolism in two Norway spruce clones after wounding and inoculations with Ophiostoma polonicum, a bark beetle-associated fungus. Plant Physiol. 109: 821-827.

Cooper WC, Jia L and Goggin FL (2004). Acquired and R-gene-mediated resistance against the potato aphid in tomato. J. Chem. Ecol. 30: 2527-2542. http://dx.doi.org/10.1007/s10886-004-7948-9

Coppola V, Coppola M, Rocco M, Digilio MC, et al. (2013). Transcriptomic and proteomic analysis of a compatible tomato-aphid interaction reveals a predominant salicylic acid-dependent plant response. BMC Genomics 14: 515. http://dx.doi.org/10.1186/1471-2164-14-515

Deng Y, Chen S, Lu A, Chen F, et al. (2010). Production and characterisation of the intergeneric hybrids between Dendranthema morifolium and Artemisia vulgaris exhibiting enhanced resistance to chrysanthemum aphid (Macrosiphoniella sanbourni). Planta 231: 693-703. http://dx.doi.org/10.1007/s00425-009-1081-5

Franzen LD, Gutsche AR, Heng-Moss TM, Higley LG, et al. (2008). Physiological responses of wheat and barley to Russian wheat aphid, Diuraphis noxia (Mordvilko) and bird cherry-oat aphid, Rhopalosiphum padi (L.) (Hemiptera: Aphididae). Arthropod-Plant Interact. 2: 227-235. http://dx.doi.org/10.1007/s11829-008-9048-1

Gunes A, Inal A, Alpaslan M, Eraslan F, et al. (2007). Salicylic acid induced changes on some physiological parameters symptomatic for oxidative stress and mineral nutrition in maize (Zea mays L.) grown under salinity. J. Plant Physiol. 164: 728-736. http://dx.doi.org/10.1016/j.jplph.2005.12.009

He J, Chen F, Chen S, Lv G, et al. (2011). Chrysanthemum leaf epidermal surface morphology and antioxidant and defense enzyme activity in response to aphid infestation. J. Plant Physiol. 168: 687-693. http://dx.doi.org/10.1016/j.jplph.2010.10.009

Horváth E, Szalai G and Janda T (2007). Induction of abiotic stress tolerance by salicylic acid signalling. J. Plant Growth Regul. 26: 290-300. http://dx.doi.org/10.1007/s00344-007-9017-4

Khattab H and Khattab I (2005). Responses of eucalypt trees to the insect feeding (gall-forming psyllid). Int. J. Agric. Biol. 7: 979-984.

Kusnierczyk A, Winge P, Jørstad TS, Troczyńska J, et al. (2008). Towards global understanding of plant defence against aphids--timing and dynamics of early Arabidopsis defence responses to cabbage aphid (Brevicoryne brassicae) attack. Plant Cell Environ. 31: 1097-1115. http://dx.doi.org/10.1111/j.1365-3040.2008.01823.x

Leszczynski B, Wright LC and Bakowski T (1989). Effect of secondary plant substances on winter wheat resistance to grain aphid. Entomol. Exp. Appl. 52: 135-139. http://dx.doi.org/10.1111/j.1570-7458.1989.tb01259.x

Libik M, Konieczny R, Pater B, Slesak I, et al. (2005). Differences in the activities of some antioxidant enzymes and in $\mathrm{H}_{2} \mathrm{O}_{2}$ content during rhizogenesis and somatic embryogenesis in callus cultures of the ice plant. Plant Cell Rep. 23: 834-841. http://dx.doi.org/10.1007/s00299-004-0886-8

Livak KJ and Schmittgen TD (2001). Analysis of relative gene expression data using real-time quantitative PCR and the $2^{-\Delta \Delta c t}$ method. Methods 25: 402-408. http://dx.doi.org/10.1006/meth.2001.1262

Maffei ME, Mithöfer A and Boland W (2007). Insects feeding on plants: rapid signals and responses preceding the induction of phytochemical release. Phytochemistry 68: 2946-2959. http://dx.doi.org/10.1016/j.phytochem.2007.07.016

Martinez de Ilarduya O, Xie Q and Kaloshian I (2003). Aphid-induced defense responses in Mi-1-mediated compatible and incompatible tomato interactions. Mol. Plant Microbe Interact. 16: 699-708. http://dx.doi.org/10.1094/MPMI.2003.16.8.699

Meng QG, Zou J, Zou JH, Jiang WS, et al. (2007). Effect of $\mathrm{Cu}^{2+}$ concentration on growth, antioxidant enzyme activity and malondialdehyde content in garlic (Allium sativum L.). Acta Biol. Cracov. Bot. 49: 95-101.

Mohase $L$ and van der Westhuizen AJ (2002). Salicylic acid is involved in resistance responses in the Russian wheat aphidwheat interaction. J. Plant Physiol. 159: 585-590. http://dx.doi.org/10.1078/0176-1617-0633

Moloi MJ and van der Westhuizen AJ (2006). The reactive oxygen species are involved in resistance responses of wheat to the Russian wheat aphid. J. Plant Physiol. 163: 1118-1125. http://dx.doi.org/10.1016/j.jplph.2005.07.014

Moran PJ and Thompson GA (2001). Molecular responses to aphid feeding in Arabidopsis in relation to plant defense pathways. Plant Physiol. 125: 1074-1085. http://dx.doi.org/10.1104/pp.125.2.1074

$\mathrm{Ng}$ JCK and Perry KL (2004). Transmission of plant viruses by aphid vectors. Mol. Plant Pathol. 5: 505-511. http://dx.doi.org/10.1111/j.1364-3703.2004.00240.x

Nugroho LH, Verberne MC and Verpoorte R (2002). Activities of enzymes involved in the phenylpropanoid pathway in constitutively salicylic acid-producing tobacco plants. Plant Physiol. Biochem. 40: 755-760. http://dx.doi.org/10.1016/S0981-9428(02)01437-7

Piubelli GC, Hoffmann-Campo CB, de Arruda IC, Franchini JC, et al. (2003). Flavonoid increase in soybean as a response to 
Nezara viridula injury and its effect on insect-feeding preference. J. Chem. Ecol. 29: 1223-1233. http://dx.doi.org/10.1023/A:1023889825129

Raskin I (1992). Role of salicylic acid in plants. Annu. Rev. Plant Biol. 43: 439-463. http://dx.doi.org/10.1146/annurev.pp.43.060192.002255

Sawada H, Shim LS, Usui K, Kobayashi K, et al. (2008). Adaptive mechanism of Echinochloa crus-galli Beauv. var. formosensis Ohwi under salt stress: effect of salicylic acid on salt sensitivity. Plant Sci. 174: 583-589. http://dx.doi.org/10.1016/j.plantsci.2008.03.013

Senaratna T, Touchell D, Bunn E and Dixon K (2000). Acetyl salicylic acid (Aspirin) and salicylic acid induce multiple stress tolerance in bean and tomato plants. Plant Growth Regul. 30: 157-161. http://dx.doi.org/10.1023/A:1006386800974

Shirley BW (1996). Flavonoid biosynthesis: 'new' functions for an 'old' pathway. Trends Plant Sci. 1: $377-382$.

Shulaev V, Silverman P and Raskin I (1997). Airborne signalling by methyl salicylate in plant pathogen resistance. Nature 385: 718-721. http://dx.doi.org/10.1038/385718a0

Smith CM and Boyko EV (2007). The molecular bases of plant resistance and defense responses to aphid feeding: current status. Entomol. Exp. Appl. 122: 1-16. http://dx.doi.org/10.1111/j.1570-7458.2006.00503.x

Sun Y, Guan ZY, Chen SM, Fang WM, et al. (2012). Identification of aphid resistance in eleven species from Dendranthema and Artemisia at seedling stage. Acta Ecol. Sin. 32: 319-325. http://dx.doi.org/10.5846/stxb201011151632

Tewari RK and Paek KY (2011). Salicylic acid-induced nitric oxide and ROS generation stimulate ginsenoside accumulation in Panax ginseng roots. J. Plant Growth Regul. 30: 396-404. http://dx.doi.org/10.1007/s00344-011-9202-3

Treutter D (2006). Significance of flavonoids in plant resistance: a review. Environ. Chem. Lett. 4: 147-157. http://dx.doi.org/10.1007/s10311-006-0068-8

Walling LL (2000). The myriad plant responses to herbivores. J. Plant Growth Regul. 19: 195-216.

Yalpani N, Enyedi AJ, Leon J and Raskin I (1994). Ultraviolet light and ozone stimulate accumulation of salicylic acid, pathogenesis-related proteins and virus resistance in tobacco. Planta 193: 372-376. http://dx.doi.org/10.1007/BF00201815

Zhang F, Zhu L and He G (2004). Differential gene expression in response to brown planthopper feeding in rice. J. Plant Physiol. 161: 53-62. http://dx.doi.org/10.1078/0176-1617-01179 